\title{
Can Use of Binocular Loupe Reduce Total Operating Time in Hemithyroidectomy? A Preliminary Study
}

Dr. Vinay S Bhat"

Associate Professor, Department of ENT Adichunchanagiri Institute of Medical Sciences, Adichunchanagiri University, Javarana Hally, Karnataka 571418, India

DOI: $10.36347 /$ sasjs.2020.v06i02.010

| Received: 12.02 .2020 | Accepted: 19.02.2020 | Published: 22.02.2020

*Corresponding author: Vinay S Bhat

Abstract

Original Research Article

Aim: This is a preliminary study which intends to compare the operating time for hemithyroidectomy with and without using binocular loupe. Materials and Methods: Total of ten patients are included in this study. Five patients each were allocated to study groups A and B. patients under group A underwent hemithyroidectomy with the use of binocular loupe and patients in group B underwent hemithyroidectomy without the use of binocular loupes. Times taken for each step of hemithyroidectomy is recorded and data analyzed. Results: Our study shows significant reduction in operating time while using binocular loupes while doing hemithyroidectomy. It also shows statistically significant reduction in time taken for steps of identification of recurrent laryngeal nerve and identification and preservation of parathyroid glands. Conclusion: Binocular loupes are inexpensive and safe tool for thyroid surgery. It reduces operating time and also enhances safety and efficacy of thyroid surgery.

Keywords: Hemithyroidectomy, Binocular loupe, recurrent laryngeal nerve.

Copyright @ 2020: This is an open-access article distributed under the terms of the Creative Commons Attribution license which permits unrestricted use, distribution, and reproduction in any medium for non-commercial use (NonCommercial, or CC-BY-NC) provided the original author and source are credited.

\section{INTRODUCTION}

Hemithyroidectomy is one of the common surgical procedures done worldwide. Surgical techniques for thyroid surgery have gradually evolved over time. Outcome of thyroid surgery depends on techniques employed in visualization of important structures during dissection [1]. In the past most of the surgeons avoided identification and dissection of recurrent laryngeal nerve and parathyroid glands due to fear of injury. These principles are no more valid and clear identification, dissection and preservation of recurrent laryngeal nerve till it enters the larynx is mandatory in modern thyroid surgery [2].

Most of the benign tumors of thyroid are unilateral and hemithyroidectomy is the treatment of choice for cosmetically disfiguring benign thyroid swellings. Surgical procedures such as near total thyroidectomy and subtotal thyroidectomy are rarely performed nowadays as total thyroidectomy seems to be better and safer alternative with lesser chances of recurrence [3]. Hemithyroidectomy though simpler compared to total thyroidectomy can lead to complications such as intra operative bleeding, injury to external branch of superior laryngeal nerve, injury to recurrent laryngeal nerve and injury to parathyroid glands. Significant amount of time is consumed in identification of these structures and total operating time increases.

Use of binocular loupes is becoming increasingly popular in head and neck surgery. Use of binocular loupes in thyroid surgery also is becoming increasingly popular. Its supposed to reduce operating time in critical steps of hemithyroidectomy. This preliminary study was carried out to evaluate operating time in hemithyroidectomy when loupe magnification is used and this data is compared with time taken for conventional hemithyroidectomy without use of surgical loupes.

\section{MATERIAL AND METHODS}

A total of ten patients with benign thyroid nodule in the right lobe of the thyroid were selected for this preliminary study. Patients were randomly allocated to two groups. Group A consisted of five patients who underwent right sided hemithyroidectomy using binocular loupe $(2.5 \mathrm{x})$. Group B consisted of five patients who underwent conventional right sided hemithyroidectomy without use of any magnification. All surgeries were performed by single surgeon with 8 years of experience in use of loupe magnification for thyroid surgeries. 
For simplicity of data collection whole procedure of hemithyroidectomy was divided into 5 steps (S1 to S5). Details of each step in depicted below (table.1). Time taken for each step (in minutes) was recorded by an assistant and was entered in the data sheet. Time taken for each step and total operating time was compared between two groups using independent $t$ test. We used SOFAstat software for analysis of data.

Table-1:

\begin{tabular}{|l|l|l|}
\hline $\begin{array}{l}\text { Step of } \\
\text { surgery }\end{array}$ & Starting point & End point \\
\hline S1 & Incision & Elevation of superior and inferior skin flaps \\
\hline S2 & Separation of strap muscles & $\begin{array}{l}\text { Ligation of superior pedicle and Identification of external } \\
\text { branch of superior laryngeal nerve }\end{array}$ \\
\hline S3 & Mobilization of thyroid lobe & $\begin{array}{l}\text { Identification and complete dissection of recurrent } \\
\text { laryngeal nerve till it enters larynx }\end{array}$ \\
\hline S4 & Identification of parathyroid glands & Complete preservation of both parathyroid glands \\
\hline S5 & $\begin{array}{l}\text { Dissection of inferior pole and separation } \\
\text { of thyroid from trachea }\end{array}$ & Skin closure \\
\hline
\end{tabular}

\section{RESULTS}

Our study included total of ten patients five each in two groups. Group A comprised of four female patients and one male patient (4:1). Group B comprised of three females and two males (3:2). Total of seven female and three males were included in the study.

Step 1 (S1): Mean of time taken in group A for $\mathrm{S} 1$ was $12.70 \pm 1.20$ mins with minimum time taken being 11 mins and maximum being 14 mins. For group B mean of time taken was $11.90 \pm 1.24$ mins with minimum time being 11 mins and maximum being 14 mins. Comparison of time taken for both the groups for $\mathrm{S} 1$ yielded a $\mathrm{p}$ value of 0.3319 which is statistically not significant

Step 2 (S2): Mean of time taken in group A for $\mathrm{S} 2$ was $21.70 \pm 1.10$ mins with minimum time taken being 20 mins and maximum being 23 mins. For group B mean of time taken was $20.40 \pm 1.95$ mins with minimum time being 18 mins and maximum being 23 mins. Comparison of time taken for both the groups for $\mathrm{S} 2$ yielded a $\mathrm{p}$ value of 0.2298 which is statistically not significant

Step 3 (S3): Mean of time taken in group A for $\mathrm{S} 3$ was $15.60 \pm 1.56$ mins with minimum time taken being 14 mins and maximum being 17.5 mins. For group B mean of time taken was $23.10 \pm 1.34$ mins with minimum time being 21 mins and maximum being 24.5 mins. Comparison of time taken for both the groups for $\mathrm{S} 3$ yielded a $\mathrm{p}$ value of $<0.001$ which is statistically significant

Step 4 (S4): Mean of time taken in group A for S4 was $12.30 \pm 0.84$ mins with minimum time taken being 11 mins and maximum being 13 mins. For group B mean of time taken was $20.30 \pm 1.52$ mins with minimum time being 18.5 mins and maximum being 22 mins. Comparison of time taken for both the groups for $\mathrm{S} 4$ yielded a $\mathrm{p}$ value of $<0.001$ which is statistically significant.

Step 5 (S5): Mean of time taken in group A for S5 was $23.90 \pm 1.98$ mins with minimum time taken being 21.5 mins and maximum being 26.5 mins. For group B mean of time taken was $24.20 \pm 0.91$ mins with minimum time being 23 mins and maximum being 25 mins. Comparison of time taken for both the groups for S5 yielded a p value of 0.7661 which is statistically not significant.

Total operating time: Mean of total operating time in group A was $87.60 \pm 1.52$ mins with minimum time taken being 86 mins and maximum being 89 mins. For group B mean of time taken was $99.90 \pm 2.97$ mins with minimum time being 95.5 mins and maximum being 102.5 mins. Comparison of total operating time for both the groups yielded a $\mathrm{p}$ value of $<0.001$ which is statistically significant (Table-2).

Table-2:

\begin{tabular}{|c|c|c|c|c|c|c|c|c|c|c|c|c|c|}
\hline & \multicolumn{2}{|l|}{ S1 } & \multicolumn{2}{|l|}{ S2 } & \multicolumn{2}{|l|}{$\mathbf{S 3}$} & \multicolumn{2}{|l|}{ S4 } & \multicolumn{2}{|l|}{ S5 } & \multicolumn{2}{|l|}{ Total } \\
\hline & & Mean & $\begin{array}{l}\text { Std } \\
\text { Dev }\end{array}$ & Mean & $\begin{array}{l}\text { Std } \\
\text { Dev }\end{array}$ & Mean & $\begin{array}{l}\text { Std } \\
\text { Dev }\end{array}$ & Mean & $\begin{array}{l}\text { Std } \\
\text { Dev }\end{array}$ & Mean & $\begin{array}{l}\text { Std } \\
\text { Dev }\end{array}$ & Mean & $\begin{array}{l}\text { Std } \\
\text { Dev }\end{array}$ \\
\hline Group & $\mathrm{A}$ & 12.7 & 1.2 & 21.7 & 1.1 & 15.6 & 1.56 & 12.3 & 0.84 & 23.9 & 1.98 & 87.6 & 1.52 \\
\hline & B & 11.9 & 1.24 & 20.4 & 1.95 & 23.1 & 1.34 & 20.3 & 1.52 & 24.2 & 0.91 & 99.9 & 2.97 \\
\hline
\end{tabular}

\section{DISCUSSION}

Operating time is an important variable which contributes significantly to cost of surgery and morbidity of the patient. Longer duration surgeries can cause significant financial burden to the patient. Any method which can reduce operating time without 
compromising on precision and safety of surgery is always a welcome step. Thyroid surgery is always considered as time consuming as many steps needs to be executed precisely so as to preserve important structures such as recurrent laryngeal nerve, external branch of superior laryngeal nerve and parathyroid glands. These precise steps cannot be compromised for reducing operating time. Many surgeons are now opting for magnification during thyroid surgeries so as to increase the precision and to reduce operating time. Binocular loupes are one such method where magnification of $2.5 \mathrm{x}$ to $4.5 \mathrm{x}$ can be achieved which enhances the precision and speed of surgery.

Loupe magnification is very helpful in identification of external branch of superior laryngeal nerve which is relatively thin and difficult to visualize in conventional thyroidectomies. Chances of injury to this nerve is varies between 10-58\% [4-6]. Use of binocular loupe makes it easier to identify this nerve thus improving safety and operating time. In our study use of binocular loupe made this step (S2) faster though statistically not significant.

Recurrent laryngeal nerve injury is supposed to be one important complication which causes significant disability to patients after thyroidectomy. Incidence of recurrent laryngeal nerve injury ranges from 0-5.8\% [710] according to various studies. Binocular loupe can definitely help surgeon to identify this nerve faster and preserve its functions precisely. In our study there was statistically significant reduction in operating time in this step (S3) of surgery.

Most dreaded complication of thyroidectomy is permanent injury to parathyroid glands leading to permanent hypoparathyroidism. Careful identification of both the parathyroid glands and their preservation with intact blood supply is essential during surgery. Binocular loupes contribute immensely in this step. Our study also shows statistically significant reduction in time take for this step (S4) of surgery.

When total operating time is considered our study shows statistically significant reduction in operating time when binocular loupes are used when compared with conventional thyroidectomy without any magnification.

\section{CONCLUSION}

This preliminary study shows significant reduction in operating time of hemithyroidectomy when binocular loupe is used. There is reduction of $12.3 \mathrm{mins}$ of operating time when binocular loupe is used. It also adds to precision of surgery enhancing the safety. This operating time may improve further for total thyroidectomy and other complex thyroidectomies with neck dissection. This study also shows significant reduction in operating time the certain steps of hemithyroidectomy such as identification of recurrent laryngeal nerve and preservation of parathyroid glands. Further study involving large study population and comparison with other magnification methods such as use of operating microscope may throw more light on advantages of binocular loupe in various types of thyroid surgeries.

\section{REFERENCES}

1. Veyseller B, Aksoy F, Demirhan H, Yildirim YS, Ertaş B, Açikalin RM, Kumral TL, Bayraktar GI. Total thyroidectomy in benign thyroid diseases. Kulak burun bogaz ihtisas dergisi: $\mathrm{KBB}=$ Journal of ear, nose, and throat. 2009;19(6):299-303.

2. Hisham AN, Lukman MR. Recurrent laryngeal nerve in thyroid surgery: a critical appraisal. ANZ journal of surgery. 2002 Dec;72(12):887-9.

3. Dralle H. Chirurgische Arbeitsgemeinschaft Endokrinologie (CAEK) der Deutschen Gesellschaft für Allgemein- und Viszeralchirurgie (DGAV) und für die Deutsche Gesellschaft für Chi- rurgie (DGCH). Identification of the recurrent laryngeal nerve and parathyroids in thyroid surgery. Chirurg, 2008;32:1358-66.

4. Lennquist S, Cahlin C, Smeds S. The superior laryngeal nerve in thyroid surgery. Surgery, 1987; 1102: 999-1008.

5. Aluffi P, Policarpo M, Cherovac C, Olina M, Dosdegani R, Pia F. Post-thyroidectomy superior laryngeal nerve injury. European archives of otorhino-laryngology. 2001 Nov 1;258(9):451-4.

6. Bellantone $\mathrm{R}$, Boscherini $\mathrm{M}$, Lombardi $\mathrm{CP}$, Bossola M, Rubino F, De Crea C, Alesina P, Traini E, Cozza T, D'Alatri L. Is the identification of the external branch of the superior laryngeal nerve mandatory in thyroid operation? Results of a prospective randomized study. Surgery. $2001 \mathrm{Dec}$ 1;130(6):1055-9.

7. Steurer M, Passler C, Denk DM, Schneider B, Niederle B, Bigenzahn W. Advantages of recurrent laryngeal nerve identification in thyroidectomy and parathyroidectomy and the importance of preoperative and postoperative laryngoscopic examination in more than 1000 nerves at risk. The Laryngoscope. 2002 Jan;112 (1):124-33.

8. Bhattacharyya N, Fried MP. Assessment of the morbidity and complications of total thyroidectomy. Arch Otolaryngol Head Neck Surg, 2002;128: 389-392.

9. Jatzko GR, Lisorg PH, Muller MG, Vette VM. Recurrent nerve palsy after thyroid operationsprincipal nerve identification and aliterature review. Surgery, 1994; 115: 139-144.

10. Lo CY, Kwok KF, Yuen PW. A prospective evaluation of RLN paralysis during thyroidectomy. Arch Surg, 2000; 135: 204-207. 